\title{
Health promotion through self-care and community participation: Elements of a proposed programme in the developing countries
} Khanindra Kumar Bhuyan*

\author{
Address: London School of Hygiene and Tropical Medicine Keppel Street, London WC1E 7HT, UK \\ Email: Khanindra Kumar Bhuyan* - kkbhuyan@hotmail.com \\ * Corresponding author
}

This article is available from: http://www.biomedcentral.com//47/-2458/4/I I

(c) 2004 Bhuyan; licensee BioMed Central Ltd. This is an Open Access article: verbatim copying and redistribution of this article are permitted in all media for any purpose, provided this notice is preserved along with the article's original URL.

\begin{abstract}
Background: The concepts of health promotion, self-care and community participation emerged during 1970s, primarily out of concerns about the limitation of professional health system. Since then there have been rapid growth in these areas in the developed world, and there is evidence of effectiveness of such interventions. These areas are still in infancy in the developing countries. There is a window of opportunity for promoting self care and community participation for health promotion.

Discussion: A broad outline is proposed for designing a health promotion programme in developing countries, following key strategies of the Ottawa Charter for health promotion and principles of self care and community participation. Supportive policies may be framed. Self care clearinghouses may be set up at provincial level to co-ordinate the programme activities in consultation with district and national teams. Self care may be promoted in the schools and workplaces. For developing personal skills of individuals, self care information, generated through a participatory process, may be disseminated using a wide range of print and audio-visual tools and information technology based tools. One such potential tool may be a personally held self care manual and health record, to be designed jointly by the community and professionals. Its first part may contain basic self care information and the second part may contain outlines of different personally-held health records to be used to record important health and disease related events of an individual. Periodic monitoring and evaluation of the programme may be done.

Studies from different parts of the world indicate the effectiveness and cost-effectiveness of self care interventions. The proposed outline has potential for health promotion and cost reduction of health services in the developing countries, and may be adapted in different situations.

Summary: Self care, community participation and health promotion are emerging but dominant areas in the developed countries. Elements of a programme for health promotion in the developing countries following key principles of self care and community participation are proposed. Demonstration programmes may be initiated to assess the feasibility and effectiveness of this programme before large scale implementation.
\end{abstract}




\section{Background}

Health promotion, self care and community participation

The international health promotion (HP) movement had its origin in the document "A new perspective on the health of the Canadians" published in 1974 under the leadership of Marc Lalonde, the then Minister of Health and Welfare Canada [1]. The report was primarily an outcome of growing concerns in Canadian government circles about the rising cost of health care and lack of proportionate rise in the health status of Canadians. For the first time in this report, a major government had acknowledged the limitations of modern medicine and health care systems in improving the health status of the population. It emphasized the role of HP as a key strategy for improving health through a holistic approach consisting of not only a medical dimension but also psychological, social and economic dimensions. Major outcomes of this document in Canada included rapid growth of programmes aimed at lifestyle featuring social marketing and health education programmes, refinement of HP practices in communities and grassroots levels, and the creation of a federal Health Promotion Directorate in 1978 [2]. Immediately following the Lalonde report, similar reports were published by the Governments of UK, US and Sweden [3].

The Ottawa charter, an important milestone in HP practice worldwide, defines HP as the process of enabling people to increase control over, and to improve, their health. Five key strategies for HP action in the charter are building healthy public policy, creating supportive environments, strengthening community action, developing personal skills and reorienting health services [4].

During the same period, the growing interest in self care (SC) and community participation (CP) was primarily an outcome of similar concerns about the limitations of professional health system in improving health. SC is defined as a process whereby a lay person functions on his/her behalf in HP and prevention and in disease detection and treatment at the level of primary health resource in the health care system [5]. Community participation (CP) emphasizes the "bottom up" approach in planning and implementation of development programmes including health development, where people are seen as active participants, compared to the conventional "top down" approach, where people are considered as passive recipients of programmes designed for them by professionals and Government officials [6]. The underlying themes of both these issues are the involvement and empowerment of people in promoting and caring for their own health.

In this article, origin and development in these areas are discussed based on the literature review from Pubmed search using key words like self care, community partici- pation and health promotion. Policy level documents, publications of different international and national health agencies in these areas have been reviewed. Some papers and documents were also downloaded from the internet. These theoretical and conceptual resources, policy level documents guide scientific and social policy discussions about promoting the health of the individuals, families and communities in developing countries. There is a growing body of evidence from the developed world that these activities indeed lead to improvement in the health status of the population. This provides a strong rationale for initiating such activities in the developing countries as well. Programme elements for SC and CP are proposed as examples that might be included when designing a HP programme in developing countries. The potential and pitfall of the proposed programme is discussed.

\section{SC: The most dominant and universal form of primary care} $\mathrm{SC}$ is not a new phenomenon. Care to sick individuals has always been provided primarily by the self and the family in all societies throughout history [7]. Current interest surrounding SC can be traced back to the 1960s and 1970s.

During the 1970s, the limitations of the professional health system were highlighted. The contribution of modern medicine in improving the health status of people was critically appraised and questioned. It was shown that mortality rates in England and Wales declined long before the advent of modern medical care during the twentieth century [8]. The negative consequences of modern medical care were exposed [9]. Professional health systems in most countries were paternalistic and people shared a state of powerlessness in it. Efforts to exercise more control over one's health and health care matters gained momentum in many countries of Western Europe and North America [10].

In the US, renewed interest in SC was rooted in the traditional American values of self-reliance, individualism, anti-elitism and popular democracy. Social movements like the Women's movement was one of the first examples of SC and the book "Our bodies, Ourselves" (The Boston Women Health Book Collective, 1971) was one of the first tools developed to promote SC among women [11]. For several reasons including the shift of pattern from infectious to chronic diseases, the change from a cure to care philosophy, the escalating cost of medical care and the rise of individualism, SC continued to grow ever since [12].

A review of literature on SC in last three decades indicates that studies on SC were broadly focussed on two areas: SC for common and chronic illnesses. A large number of studies across different countries, using a variety of 
research methods, have consistently shown that SC is the most dominant form of primary care in both developed countries with better health infrastructure and higher literacy rates as well as in developing countries, where the majority of the people are poor and do not have access to professional health care.

In the health diary method to study health care behaviour, participants record perceived illness symptoms and how they respond to them over a period of time. Several health diary studies reveal that only a small proportion of illness is cared by professionals, much of the illness is cared by the individual and the family $[13,14]$. Mothers take the most active part in caring for ill children within the family [15]. Use of over-the-counter medicine is the most frequently reported illness management activity in some studies [16-19].

Population based cross sectional studies reveal similar findings. At any point of time, majority has physical symptoms and only a small proportion seeks profession medical care for help. Most of these symptoms are managed by SC or care from family members or friends [20].

Studies conducted at national level in different countries also reveal similar distribution between SC and professional care. For example, a study in early sixties showed that in England and Wales, a vast proportion of morbidity related to both common illness and chronic illness was not treated by medical practitioners. Indeed, the treatment provided by medical practitioners was only the "tip of iceberg" [21]. Similar findings were reported from an international study on health care utilization in three different countries- US, UK and Yugoslavia [22].

A recent study in Mexico shows that SC represents the most common response to illness. Important determinants of SC are socioeconomic conditions (common among poor) and place of residence (common in the rural areas) [23].

It is estimated that 65 to $85 \%$ of all health care is provided by the individual or the family, without professional intervention, using folk, non-allopathic or allopathic technology. SC appears to encompass activities related to $\mathrm{HP}$, disease prevention, illness and injury treatment, chronic disease management and rehabilitation. The family functions as a basic health care unit with an elaborate system of beliefs and procedures, many of which are rooted in the local culture. All levels of professional primary care are thus only supportive to SC and modest facilitation of it has the potential to improve the health and socioeconomic status of the whole population $[10,24]$.

\section{Categorization of SC}

Some researchers have classified SC into health SC, which includes activities aimed at maintaining and improving health and medical SC, which includes activities undertaken in response to medical problems [25]. Others have proposed four different types of SC: i) Regulatory SC, which includes routine health maintenance activities such as eating, sleeping and personal hygiene, ii) Preventive $\mathrm{SC}$, which refers to practices like exercising, dieting, selfexamination, iii) Reactive SC, which refers to self-initiated responses to symptoms that have not yet been labelled by physician as illness, and iv) restorative SC, which is compliance to a professionally prescribed medication regimen [26].

Rapid growth of SC activities in North America and Western Europe From 1970s onwards, there has been a massive growth of SC activities in North America and Western Europe. An explosion of health texts on SC has occurred.

Information technology has revolutionized the availability of information on health to the consumers. The area of consumer health informatics, which deals with issues related to information on health and medical care to consumers through the application of information technology, has expanded rapidly [27]. In the US, exciting development in this area include designing a new generation of software programmes for home management of many chronic diseases like AIDS, substance abuse, diabetes, depression, formation of electronic self-help groups. In effect, the industrial age medicine is being replaced by information age health care in the US. In industrial age medicine, developed nearly a century ago, health care was primarily provided by professionals at primary, secondary and tertiary levels overlooking SC, which is the most pervasive form of health care. In information age health care, lay persons manage a vast proportion of illness by themselves using information from various sources and as a result, the role of professionals in health care diminishes. The information age health care is contrasted with industrial age medicine in Figure 1[28].

The numbers of self-help groups, which are voluntary groups formed by individuals affected by a particular disease or chronic condition for mutual caring, burgeoned. Early examples of such groups include Alcoholic Anonymous in the US and subsequently these were formed for many chronic illnesses including psychiatric disorders, diabetes, hypertension, different types of cancer and dementia [29]. In Germany, the number of such groups has grown to about 60000 by the year 1995 [30].

SC clearinghouse supports the formation and continuation of self help groups, links community and professionals to these groups and provides information, education 
Industrial age medicine
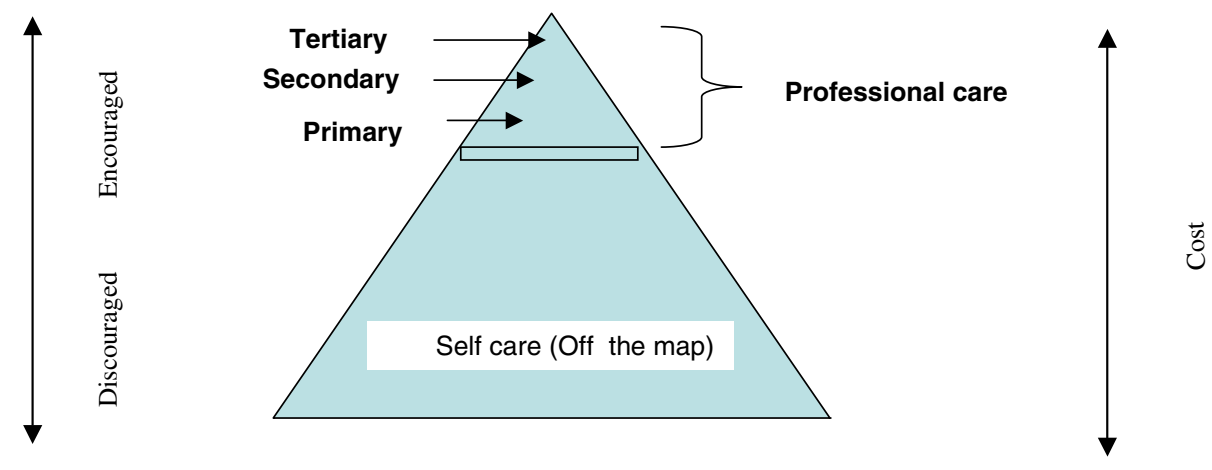

Information age health care
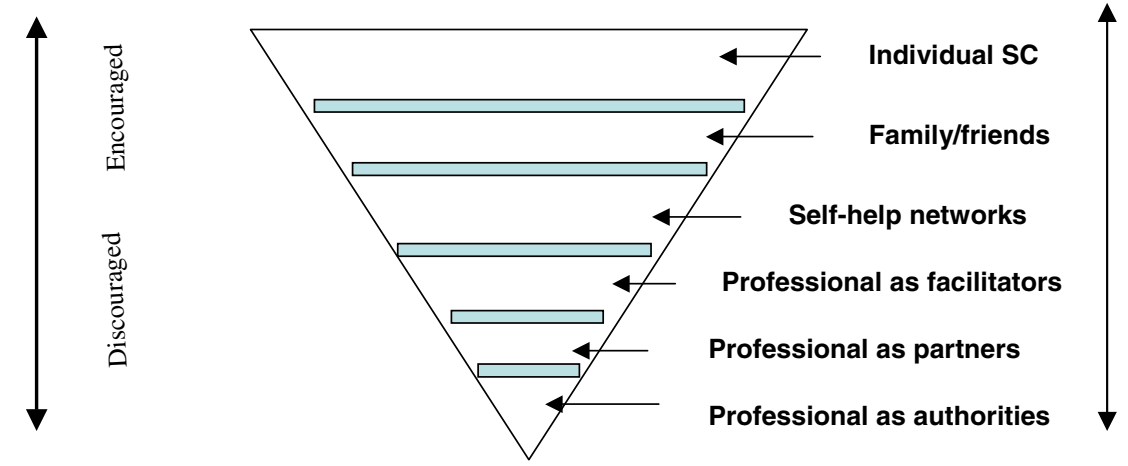

$\dot{\overrightarrow{8}}$

Figure I

Changing map of health care (Adapted from reference 28)

and consultative services. The first SC clearinghouse was established in the US in 1964. By 1987, the number had grown to fifty four in North America [31]. In recent years, SC clearinghouses have been established in several countries [32].

Access to medical care technology and drugs for lay person has increased tremendously. In the US, it is estimated that the "do-it-yourself" medical equipment industry is worth 10 billion US dollars [33]. Access to non-prescription medicine in the UK increased greatly following reclassification of some drugs by the Government from prescription only status to allow sale in pharmacies over the counter during late 1980s. By 1994, sale of over-thecounter drugs was equivalent to one-third of the total drugs bill of the National Health Service. Similar deregulation of drugs was implemented in some countries of Europe and North America as well as in Australia and New
Zealand, primarily as a measure to pass on some of the costs of health care to consumers [34].

At the international level, the first symposium on SC was held in European headquarter of World Health Organization (WHO) in Copenhagen in 1975. It examined the lay contribution to health care, clarified roles and functions and identified priority research areas [5]. In 1983, a publication by the European office of the WHO examined various aspects of SC in several countries of the region. [35].

\section{SC is in its infancy in the developing countries}

Barring a few studies on SC behaviour of individuals, literature on most other SC activities is scarce from developing countries. There has not been any explosion of SC technology and texts. Lay persons are yet to become conscious of the enormous potential among them for their HP. Professional health system is elitist and lay persons 
are yet to exert their right over their bodies in doctorpatient interaction. The philosophy and practice of SC are still in infancy in these countries.

\section{Partnership between lay person and professionals}

Partnership between lay persons and professionals is essential for promoting SC. In practice, roles of lay persons and professionals in such partnership vary widely. At one end in many SC activities, such as the Women's Health Movement in the US, the role of professionals is quite limited. In many other SC activities, input from the professionals is substantial. In some studies, it is observed that presence of receptive professionals is a precondition for development of SC [36]. A survey of SC education programmes in the US revealed that, despite SC being branded by the American media as a popular social movement, more than half of such programmes were funded by health service delivery organizations and were run by professionals such as registered nurses, health educators, physicians as instructors rather than lay persons [37]. In Canada, Health Canada initiated a number of activities for increasing the support of SC by health professionals. One such initiative, SC project, developed a framework for registered nurses and physicians for supporting SC in 1994. This study identified three categories of programmes (integrated education and support programmes, self-help groups and support groups) and four categories of tools (print and audiovisual tools, telephone help lines, computer based tools and self-monitoring tools) as useful adjuncts for professional support of SC [38].

\section{Community participation or community involvement in health development (CIH) \\ Origin of the idea of $\mathrm{CP}$ or $\mathrm{CIH}$}

Growing disillusionment with prevailing development strategies for the failure to improve the lives of the majority of people in developing countries led to a re-thinking of the entire development process in the 1970s, which ultimately led to the emergence of the idea of CP [39]. It was pointed out that most of the earlier strategies were planned for the people by outsiders, where people were considered as mere recipients and the transfer of technology was thought to be adequate for their development. Emphasis was laid on the active participation of people and there was a general concern to make development strategies more people-centred, based on their own aspirations and ideas. Since then the idea of CP emerged as a fundamental component of any development strategy, at least in theory, including health development.

\section{Different interpretations of CP and role of information and education in promoting $C P$}

Since its inception, CP has been interpreted differently. According to one school, communities can be mobilised to participate in the development process merely by increasing their knowledge and awareness about development projects and programmes, lack of which is perceived as the main reason behind their non-participation. The other school advocates a radical change in the prevailing development process. Participation, in this sense, is viewed as "empowerment", where people exercise more control over the decision-making process and participate from the planning stage itself [6]. Participation has also been viewed as a ladder with different levels. Information, consultation and placation are at the lower levels, which represent only tokenism for participation, whereas delegated power and citizen control at the upper levels represent citizen empowerment [40]. Still another view is that it is a continuum with different inter-related, overlapping stages; with information and consultation with communities by professionals at one end, to the collaboration and assuming of full responsibility by communities at the other [41].

The WHO study group on CIH suggested two broad ways of promoting CIH: a) through awareness and understanding of health and health problems and b) through access to information and knowledge about health service programmes and projects [42].

Partnership between professionals and people in generating health information through participatory planning is crucial for CP. The involvement of people in generating information leads to the ownership and utilization of the knowledge that has been generated [41].

Rapid development of theory and practice of CP and universal acceptance of CP as a strategy for HP

Gradually the idea of CP gained wide acceptance as a strategy for HP. Activities implemented to promote CP range from projects in small geographic areas to national vertical programmes for addressing a particular health issue, to overall primary health care (PHC) at the national level. On the theoretical side, frameworks for the monitoring and evaluation of participation in disease control programmes were developed $[43,44]$. A conceptual framework was also developed for measuring participation in PHC [45]. Many disease control programmes, ranging from guinea worm eradication to malaria control, were implemented in participatory ways $[46,47]$. In the US, a national HIV control programme was implemented with a major planning exercise involving thousands of community residents and professionals in all the states [48]. Efforts were made to improve consumer participation in the national health services in Australia [49]. There are numerous examples of successful CP in small-scale projects, often managed by non-governmental organizations (NGOs), but they are never replicated on a much larger scale [50]. Success stories include community oriented primary care, which originated in rural pre-apart- 
heid South Africa and influenced health programmes in several countries like Israel, UK and the US [51]. In the census based impact oriented (CBIO) approach to PHC, implemented in selected areas of Bolivia, local health priorities were determined based on epidemiological information by the people themselves [52]. In Mexico, a module programme of the Ministry of Health was implemented to promote CP in PHC [53].

At the international level, CP became an essential element of health development programmes sponsored by international donors. Multilateral agencies like the World Bank and the Organization of Economic Cooperation and Development have accepted the principle and initiated activities for promoting $\mathrm{CP}$ in the development programmes they supported $[54,55]$. CP was one of the main principles of PHC in the global strategy of Health for All by WHO [56].

\section{Discussion \\ A window of opportunity: Elements of a proposed programme for HP in developing countries}

In the foregoing discussion it is observed that the ideas of HP, SC and CP emerged almost all at the same time, out of the concerns about the limitations of the professional health systems. Self-reliance and empowerment are the underlying themes of SC and CP. These two concepts are rooted in the broad democratic principles of rights and duties of individuals to participate in the activities that affect their lives. In the literature too, there is considerable overlap between these areas and terms like $\mathrm{CP}$, consumer participation, citizen participation, SC and self-help. For instance, concepts of citizen participation in health encompass activities related to SC and CP. Based on the experience of Western Europe and North America, two main approaches to citizen participation have been summarized. The first is the participation of the people in the decision making process, where people participate in policy formulation, planning and implementation. The second concerns participation in community level activities, which includes a broad spectrum of groups such as selfhelp groups, voluntary organizations and social movements, such as the women's movement [57]. In the HP framework aimed at achieving health for all Canadians, SC was proposed as one of the three key mechanisms [58].

During the last three decades, growth of SC activities has been witnessed mostly in developed countries where health services are accessible to vast majority of the population. It is in its infancy in developing countries, even though uneven distribution of professional resources leaves a vast proportion of rural and poor masses without access to professional health care. For instance, in India it is estimated that about $75 \%$ of the professional health infrastructure, medical manpower and health resources are located in the urban areas, where only $23 \%$ of the population live [59]. Lower socio-economic status increases the vulnerability of the poor to illness and reduces their ability to cope with it. Similarly large scale programmes to improve CP for HP are yet to be initiated in the developing countries. There is a great window of opportunity for $\mathrm{HP}$ among the disadvantaged and poor people of developing countries through SC and CP.

A broad outline is suggested for the implementation of such a programme primarily in developing countries, following five key strategies of the Ottawa charter for HP and following principles of SC and CP. Figure 2 shows the health care pyramid and proposed model for HP programme. Health and HP lie at the base of the pyramid. At this level, health SC of the individual is the determinant of one's lifestyle and behaviour. Here lay person plays the most predominant role for his/her HP. The second level is PHC, which is defined as the essential health care based on practical, scientifically sound and socially acceptable methods and technology made universally accessible to individuals and families in the community through their full participation and at a low cost that the community and the country can afford to maintain at every stage of their development in the spirit of their self determination [56]. It is the first level of contact for individuals, the family and the community with the national health system. At this level too, lay persons play a major role in their health care, supplemented by professionals. The next levels are secondary and tertiary care respectively, having highly skilled health workers and sophisticated diagnostic and therapeutic technology, where progressively complex health problems are dealt with [60]. Here professionals play the predominant role.

The strategies of the proposed HP programme may be primarily directed to the first two levels, that is, health and PHC, where SC is the most dominant form of health care. These strategies are not mutually exclusive but synergistic. Similarly, the same strategy may be relevant for both the levels of health care. Structural and policy level actions may be directed for promoting SC and CP. A national body, with members from the community, professionals and officials, may be created for policy formulation and for providing overall supervision for designing and implementing the programme in co-ordination with the provincial level organisations. Budgetary allocation for promoting these activities should be made.

SC clearinghouses may be established to spearhead the programme at the provincial level, in consultation with lay persons, professionals and national and district level Officials. SC clearinghouse may co-ordinate the design and dissemination of SC information, provide training to the health workers and lay persons, provide consultative 


\section{Health care pyramid and model for HP programme}

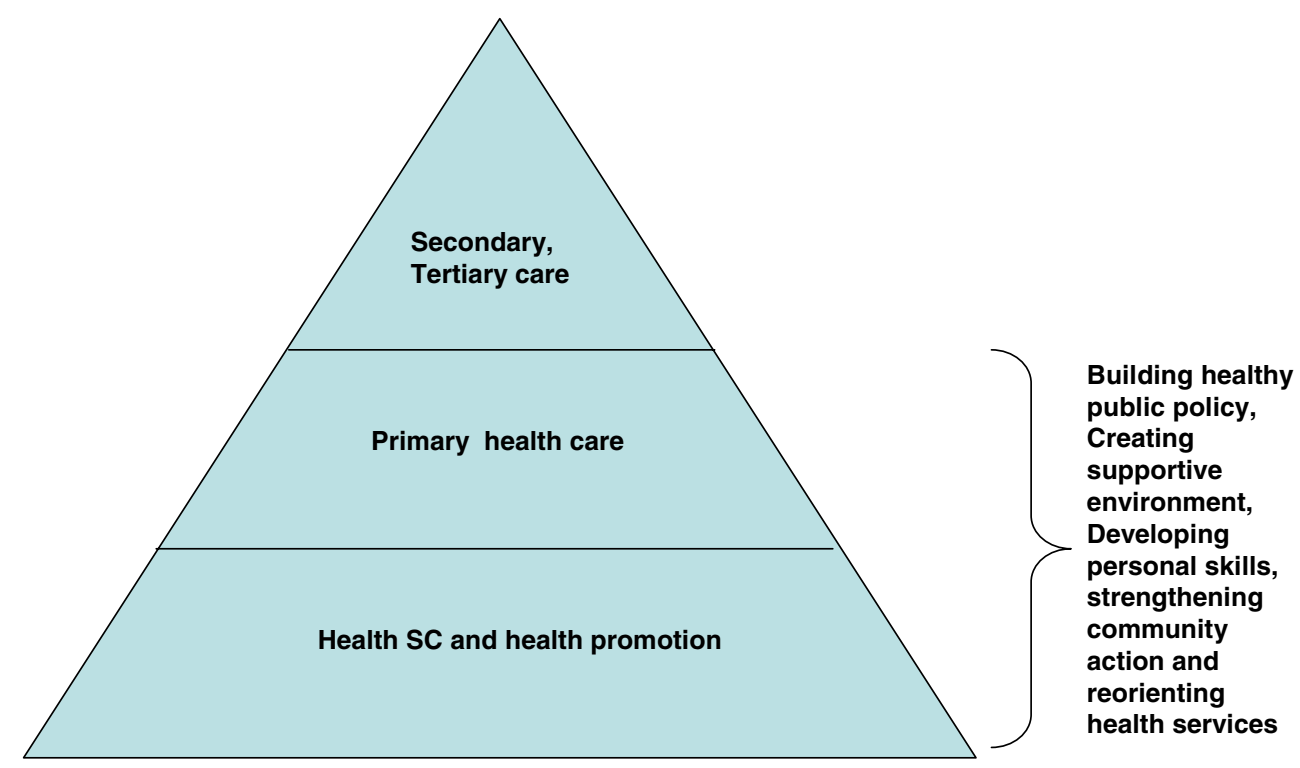

Figure 2

Health care pyramid and model for HP programme

services for reorientation of the health services, and monitor and evaluate the programme.

Activities may be directed to create a supportive environment and strengthen community action at the grass roots level. SC may be promoted at work places and schools. NGOs and other community based organisations may promote SC in the community, based on the SC information generated through a participatory process as mentioned later.

One of main strategies of this programme may be to increase personal skills of lay person for SC. This component of the programme may be designed and implemented at the district level in co-ordination with the SC clearinghouse. A district health system is the basic unit of national health systems in many countries. It is at this level that national programmes can be adapted to local situations [61]. Basic SC information may be generated by lay persons in partnership with professionals and government officials through a participatory planning process.

This strategy may be implemented through the different stages of community organisation model as follows: 1) Community analysis, 2) Design and initiation, 3) Implementation, 4) Maintenance-consolidation and 5) Dissemination and reassessment [62].

\section{Community analysis: participatory planning}

A core group (CG) or executive committee (EC) is usually responsible for long term planning and coordination as well as implementation of community-wide health programmes [63]. A district level CG or EC, comprising of representative members of the community, professionals and officials from health and other development sectors may be constituted for planning and providing overall 
supervision. Participatory planning exercises (participatory needs assessment) may be conducted jointly by the communities and professionals for analysing the health situation in the district and developing strategies to address them. Existing routine data from different sources may be analysed to understand the health profile of district population. For understanding the health and disease-related perceptions and practices of individuals, especially SC practices in their social and cultural context, qualitative and quantitative methods may be employed.

Special attention may be given for the HP of the hard to reach groups. Information alone is not sufficient for their $\mathrm{HP}$, structural and social barriers need to be addressed simultaneously.

\section{Design and initiation}

Based on this exercise, appropriate action plan may be devised. The roles and responsibilities of individuals and the community and that of the sectoral administrations may be defined. The roles of the individual and the community can be formulated as SC information.

For communicating SC information, a wide range of tools including print and audio-visual tools, computer based tools, tele-communication based tools may be used. Web sites on SC may be designed to communicate this information. Electronic discussion forums may be formed to discuss various issues on SC and HP. A telephone help line may be set up for SC of common illnesses.

One such print-based tool could be a personally held SC manual and health record (SCMHR). The first part of the SCMHR may contain basic SC information. This information may be arranged in many creative ways. One way is to put it in three sections: SC and the individual, SC and the family, SC and the community; each describing what an individual can do for HP of herself/himself, family and the community respectively. Alternatively, SC information may be put in four different sections based on the type of SC [26]. For instance, information on regulatory SC may contain locally appropriate scientific information on diet, nutrition, personal hygiene and sleep. Preventive SC may include information on exercise, dieting and selfexamination. Reactive SC may include information on self management of illnesses and when to approach a professional and so on. SC information should be simple, rooted in the local social and economic situation, and be appropriate and actionable. The second part of the SCMHR, which may also be designed jointly by lay person and professionals, may contain outlines of various health records like birth certificate, immunization card, growth chart, child health card, drugs prescriptions and discharge slips (for hospital admission), to record important health and disease related events of the individual. The SCMHR of a baby may be provided to his/her parents at the time of birth to be retained for life. Basic SC information is likely to empower the parents to promote the health of their baby during childhood, and the individual as he/she grows up. SC information may be formulated for pregnancy in the case of woman. SC information may be designed for various chronic diseases like diabetes mellitus, hypertension and psychosis. Such material can be annexed to the SCMHR through the health system, if the need arises. In place of SCMHR, electronic tools like CD ROM may also be used for communicating SC information to each individual and record his/her important health related events, if majority of the population have access to computers.

\section{Implementation and maintenance-consolidation}

SC information generated through the participatory process mentioned above, may be disseminated using a range of tools and employing a variety of channels as discussed below:

\section{The individual and the family}

The greatest asset for mobilizing people for HP may be the people themselves. For instance, if a student is informed and educated on SC and CP, he/she can be further motivated to spread the message to his/her family members and neighbours. This creates the potential of involving illiterate poor people in rural areas of developing world. Moreover an informed and empowered individual within a family can be carer for all the members.

\section{Community health workers (CHWs) or village level development workers}

CHWs are the bridge between the formal health sector and communities in many countries of the world. They are from communities where they work, and should be selected by communities and should be supported and trained by the health system. Their functioning has been reviewed recently and issues like their capacity building has been discussed [64]. CHWs may play a role in mobilizing individuals and families. Similarly, field level workers of other development sectors may also be involved in the programme. Strong professionalism of formal health sector towards curative medicine rather than public health and preventive medicine in most countries, combined with the need for inter-sectoral coordination for HP, may warrant maximum utilization of the workers from other development sectors.

Social mobilisation through community based organisations, NGOs and private sector

As mentioned already, NGOs and the private sector may be actively involved in the programme. 


\section{Monitoring and evaluation}

Monitoring and evaluation of the programme may be done in a participatory way, based on which the programme may be redesigned periodically. For monitoring, process level indicators may track the progress of the activities accomplished under each strategy against the targets that are set at the beginning of the intervention. Evaluation can be done at regular interval to assess the secular trend in knowledge and practice related to SC. One of the methods of evaluation may be to compare baseline data for a variety of indicators with the post intervention figures to assess the trend.

\section{Evidence base for HP and SC interventions}

Before considering implementation of any public health programme, several issues such as appropriateness, feasibility, effectiveness, cost effectiveness and potential need to be carefully considered. Generating an evidence base for evaluating HP programmes, consisting of interventions directed at different levels like developing personal skill at individual level, social mobilization at the community level and advocacy to influence public policy, is complex and multidimensional. Experimental studies like randomised control trials, considered as the gold standard in evidence based medicine, have only a limited role in generating evidence for HP programmes. The evidence base on such programmes needs to be generated from several different sources including experimental studies and observational studies using qualitative and quantitative methods [65].

There is evidence from a large number of studies that SC and HP interventions work. Moving a step further from these studies, which are conducted in the 'controlled' situations, there are also examples of successful large-scale HP programmes in the 'real world'. In a trial, 391 college students were randomly assigned to intervention or control groups. The intervention, which consisted of providing SC information, resulted in positive changes in the attitude and belief in the intervention group [66]. A medical SC programme consisting of 11 sessions of educational intervention produced substantial improvement in health-related knowledge, health skill performance and health action in the intervention group compared to the control group. However there was no evidence that the intervention had any effect on health status or medical care utilization [67].

SC education has been found to be effective in improving the patient condition for a variety of chronic diseases. These diseases include osteoarthritis of knee [68], chronic pain [69,70], headache [71] and back pain [72,73]. Systematic review of large number of studies has showed the clinical and cost effectiveness of self-help treatments for anxiety and depressive disorders [74] and different com- mon disorders [75] and chronic disorders [76,77]. Metaanalysis of studies has showed that SC interventions are effective in improving the outcome and reducing the use of health services in adults with asthma [78]. Conveying appropriate SC information to the patient reduces the use of the health services by $7-17 \%$ [79]. The effectiveness of self help groups has been studied and there is indication that self help groups are associated with higher improvements compared to the controls [80].

A review of several international surveys on SC practices has concluded that SC practices are often beneficial and SC appears to be a universal behaviour [81].

At the work place, providing SC information to employees is an effective way of reducing employer's health cost. In a company, a programme was implemented using a guide, which contained information on SC of illness and when to refer to professionals. Claim data analysis at baseline and 1 year after the programme indicated a saving of $\$ 39.65$ per employee (24\% reduction in cost) [82].

In large community wide projects, SC information was found to be effective in empowering people to manage their illness resulting in reduction of the use of professional services. Healthwise, a non-profit organization based in US, implemented in a large community wide SC information project, Healthwise Communities Project, in Southwest Idaho, US during 1996-1999. In the project, a SC handbook (Healthwise Handbook) was distributed to each household in the area and a telephone advice line was provided and a web site on SC was set up. The handbook contained SC information on over 180 common medical problems and when to consult a professional. Workshops were organised in the schools, businesses and churches to inform consumers on SC. Workshops were also organised for doctors, nurses and other providers to inform them on working better with informed consumers. The study to assess the effectiveness of the project indicated that the intervention increased the use of SC resources resulting in some reduction of the use of health services [83].

Following the success of this project, similar projects were initiated in the US and in Canada. In the Partners Health Initiative project, implemented in parts of South Carolina and Georgia of US, 154000 families received the Healthwise Handbook. Evaluation of the project indicated that use of the handbook resulted in reduced hospital visits with an estimated cost saving of $\$ 34.5$ million during 30 months of the initiative. For every dollar invested, there was a saving of 11 dollars of health care costs [84]. Encouraged by the success of these projects, each family in the British Columbia province of Canada has been given a Healthwise Handbook. 
There is also evidence that large HP programmes are effective in reducing morbidity, mortality and improving quality of life. In Canada, HP programmes began in the 1970s. There has been an increase in life expectancy at birth and reduction of infant mortality rates in Canada between the 1970s and 1990s. Nearly 10 million Canadians have reported improvement in their personal health practices such as reduced alcohol consumption, improved eating habits, increased physical activity and $67 \%$ of them attributed this to increased awareness of health risks. The validity of this self-reported behaviour is further supported by the fact that there has been a corresponding decline in cardiovascular mortality attributed to these healthier lifestyle and improved medical care [2].

\section{Potential}

Successful implementation of the proposed programme may lead to the empowerment of individuals and communities. The potential public health benefits of the proposed programme are mentioned below.

\section{HP through SC and CP}

A participatory way of generating and disseminating SC information is likely to empower lay persons and result in healthy behaviour, which may lead to their HP. Conventional health education is often didactic. A vast majority of the people from the developing world still do not have access to the basic information for HP. The proposed programme may address these two drawbacks as communities and professionals design SC information jointly and this information is put at the disposal of each individual from a very young age.

\section{Reduction of health care cost}

Cost of health care is constantly on the rise. Successful implementation of this programme has the potential to reduce cost of health care in a variety of ways as shown in different studies already mentioned.

\section{Facilitation of health planning, management and research}

If SCMHR were used as a tool in the programme, in combination with traditional sources, it may improve the health information system, which may facilitate health planning and management. Those epidemiological studies which depend on health records like case control studies and retrospective cohort studies may be greatly facilitated in the long run.

\section{Pitfall}

Confidentiality about the health and disease related information of an individual

If SCMHR were used as a tool for recording important events of one's life, confidentiality of this information would have to be protected. This can be addressed at the time of designing the SCMHR, by deciding what informa- tion to include in the manual, to whom all these information be made accessible.

\section{Summary}

$\mathrm{HP}$, SC and CP are emerging and dominant themes in health mostly in developed countries. There is a great window of opportunity for initiating a HP programme following principles of SC and $\mathrm{CP}$ in the developing countries. Elements of such a HP programme and broad outline for implementation are discussed. Demonstration programmes need to be initiated at the district level to assess appropriateness, feasibility, effectiveness of such a programme before any attempt of large-scale implementation.

\section{Abbreviations}

(CHW) community health worker

(CIH) community involvement in health development

(CP) community participation

(CG) core group

(EC) executive committee

(HP) health promotion

(NGOs) non-governmental organizations

(PHC) primary health care

(SC) self-care

(SCMHR) self-care manual and health record

(UK) United Kingdom

(US) United States of America

(WHO) World Health Organization

\section{Competing interests}

None declared.

\section{Acknowledgement}

The author is deeply indebted to Prof. SB Rifkin, who reviewed the paper and inspired me with many suggestions, based on which much of the paper was rewritten. I am grateful to the reviewers, whose critical comments have greatly improved the paper. I am also grateful to my friends and colleagues, who reviewed the draft and gave many useful suggestions.

\section{References}

I. Lalonde M: A new perspective on the health of Canadians. Ottawa: Health and Welfare Canada 1974.

2. Hancock T, Labonte R: Lessons from Canada. In: The Evidence of Health Promotion Effectiveness: Shaping public health in a New Europe, 
Part Two Evidence Book, A report to European Commission by the International Union for Health Promotion and Education Edited by: Boddy D. Brussels: International Union for Health Promotion and Education; 2000:134-136.

3. Hancock T: Lalonde and Beyond: Looking back at "A new perspective on the health of Canadians". Health Promot 1986 I:93-100.

4. World Health Organization: Ottawa Charter for Health Promotion. Geneva 1986.

5. Levin LS, Katz AH, Holst E: Self care: lay initiatives in health. London: Croom Helm 1977.

6. Oakley P: Community involvement in health development: An examination of critical issues. Geneva: World Health Organization 1989.

7. Dean K: Self care responses to illness: A selected review. Soc Sci Med I98I, I 5A:673-675.

8. Mckeown T: The Role of Medicine: Dream, Mirage, or Nemesis. London: The Nuffeld Provincial Trust Hospital 1976.

9. Illich I: Medical Nemesis: The Expropriation of Health. New York: Pantheon Books 1976.

10. Levin LS: Self-care oriented health education from the perspective of WHO role. (HED/80.I). Geneva: World Health Organization 1978.

II. Kickbusch I: Self-care in health promotion. Soc Sci Med 1989 , 29:125-I30.

12. Padula CA: Self-care and the elderly: Review and implications. Public Health Nurs 1992, 9:22-28.

13. Demers RY, Altamore R, Mustin H, Kleinman A, Leonardi D: An exploration of the dimensions of illness behavior. J Fam Pract 1980, I I:I085-1092. [Pubmed Abstract]

14. Tonai S, Maezawa M, Kamei M, Satoh T, Fukui T: Illness behavior of housewives in a rural area in Japan: a health diary study. Cult Med Psychiatry 1989, 13:405-417. [Pubmed Abstract]

15. Dahlquist G, Sterky G, Ivarsson Il, Tengvald K, Wall S: Health problems and care in young families - load of illness and patterns of illness behaviour. Scand J Prim Health Care 1987, 5:70-86. [Pubmed Abstract]

16. Lawrence DM, Schank MJ: Health care diaries of young women. J Community Health Nurs 1995, I 2: |7|-|82. [Pubmed Abstract]

17. Stein CM, Gora NP, Macheka BM: Self-medication in urban and rural Zimbabwean communities. $\mathrm{Br} J$ Clin Pharmacol 1989 27:74|-747. [Pubmed Abstract]

18. Haider S, Thaver SH: Self medication or self care: implication for primary health care strategies. J Pak Med Assoc 1995 45:297-298. [Pubmed Abstract]

19. Delgado E, Sorensen SC, Van der Stuyft P: Health seeking behaviour and self-treatment for common childhood symptoms in rural Guatemala. Ann Soc Belg Med Trop 1994, 74:16|-268. [Pubmed Abstract]

20. D Hannay: The symptom iceberg: A symptom of community health. London: Routledge and Kegan Paul 1979.

21. Last JM: The Iceberg: "Completing the clinical picture" in general practice. Lancet 1963, 2:28-31.

22. White KL, Dragana A, Pearson JH, Marby AR, Sagen OK: International comparison of medical care utilization. $N$ Engl J Med 1967, 277:520.

23. Leyva-Flores R, Kageyama ML, Erviti-Erice J: How people respond to illness in Mexico: self-care or medical care? Health Policy 200I, 57:I5-26.

24. Williamson JD, Danaher K: Self-care in health. London: Croom Helm 1978.

25. Vickery DM, Iverson DC: Medical self care and use of the medical care system. In: Health promotion in the workplace Edited by: O'Donnell MH, Albany JS. NY: Delmer; 1994.

26. Barofsky I: Compliance, adherence and the therapeutic alliance: Steps in the development of self care. Soc Sci Med 1978, 1 2:369-376.

27. Eysenbach G: Consumer Health Informatics. BMJ 2000, 32:1713-1716

28. Ferguson T: Consumer Health Informatics. Healthcare Forum Journal 1995, 38:28-33.

29. Katz AH, Bender E: The strength in Us: Self-Help Groups in the Modern World. New York: Franklin-Watts 1976.

30. Balke K: Status of Health Policy and possible support to self help groups. Gesundheitswesen 1995, 57:706-709. [Pubmed Abstract]
31. Wollert R: Self-help clearing-houses in North America: a survey of their structural characteristics and community health implications. Health Promot 1988, 2:377-379.

32. American Self-help Group Clearinghouse [http://www.mental help.net/self-help/self.php?id=859]

33. Levin LS: Public Participation in health care quality: Duncun Memorial Lecture. J Epidemiol Community Health I995, 49:348-353.

34. Blenkinsopp A, Bradely C: Over the Counter Drugs: Patients, society, and the increase in self medication. BM] 1996, 3 I 2:629-632.

35. World Health Organization: Self help and health in Europe. Copenhegen: World Health Organization European Office 1983.

36. Barofsky I: Compliance, adherence, and the therapeutic alliance: Steps in the development of self-care. Soc Sci Med 1978 , I 2:369-376.

37. DeFriese GH, Woomert A, Guild PA, Steckler AB, Konrad TR: From activated patient to pacified activist: a study of the self-care movement in the United States. Soc Sci Med 1989, 29:195-204.

38. Health Canada: Supporting self care: The contribution of Nurses and Physicians. [http://www.hc-sc.gc.ca/hppb/healthcare/ pubs/selfcare/listof.htm].

39. Oakley P, Marsden D: Approaches to participation in rura development. Geneva: International Labour Office 1984

40. Arnstein SA: A ladder of citizen participation in the USA. Journal of American Institute of Planners 1969, 35:216-224.

41. Rifkin SB, Pridmore P: Partners in planning: information, participation and empowerment. London: TALC Macmillan Education Limited 200I.

42. World Health Organization: Community Involvement in Health Development: challenging health services. Geneva I99I.

43. Bermajo A, Bekui A: Community participation in disease control. Soc Sci Med 1993, 36: I | 45- I I 50.

44. Manderson L: Community participation and malaria control in South East Asia: defining principles of involvement. Southeast Asian J Trop Med Public Health 1992, 23:9-I7.

45. Rifkin SB, Muller F, Bichmann W: Primary Health Care: On measuring participation. Soc Sci Med 1988, 26:930-940.

46. Cairncross S, Braide El, Burgi SZ: Community participation in the eradication of guinea worm disease. Acta Trop 1996 , 6I:|2|-|36.

47. Riji HM: Adopting primary health care approach in malaria control in Malaysia: lesson in community participation. Southeast Asian J Trop Med Public Health 1992, 23: 18-22. [Pubmed Abstract]

48. Dearing JW, Larson RS, Randall LM, Pope RS: Local reinvention of the CDC HIV prevention community planning initiative. Community Health 1998, 23: I I3-126.

49. Johnson A, Silburn K: Community and Consumer participation in Australian health services-An overview of organizational commitments and participation processes. Aust Health Rev 2000, 23: $|13-12|$

50. World Health Organization: The Challenge of Implementation: District Health Systems for Primary Health Care. Geneva 1988.

51. Mullan F, Epstein L: Community-oriented primary care: new relevance in the changing world. Am J Public Health 2002 , 92: 1748- 1755 .

52. Perry H, Robinson N, Chavez D, Taja O, Hilari C, Shanklin D, Wyon J: Attaining health for all through community partnerships: principles of the census-based, impact oriented (CBIO) approach to primary health care developed in Bolivia, South America. Soc Sci Med 1999, 48:1053-1067.

53. Zakus JD: Resource dependency and community participation in primary health care. Soc Sci Med 1998, 46:475-494.

54. World Bank: The World Bank and participation. Washington DC 1994.

55. Organization for Economic Cooperation and Development: Promoting participatory development: from advocacy to action. Paris 1994

56. World Health Organization: Primary Health Care: Report of the International Conference on Primary Health Care. Geneva 1978

57. Bracht N, Tsouros A: Principles and strategies of effective community participation. Health Promot Int 1990, 5:199-208.

58. Health and Welfare Canada: Achieving health for all: A framework for Health Promotion. Ottawa: Ministry of Supply and Services Canada 1986 
59. Patil AV, Somasundaram KV, Goyal RC: Current health scenario in rural India. Aust J Rural Health 2002, 10:129-135.

60. World Health Organization: Technical Report Series 746. Geneva |991.

61. World Health Organization: Information support for new public health action at district level. Geneva 1994.

62. Bracht N, Kingsbury L, Rissel C: A Five-stage Community Organization Model for Health Promotion: Empowerment and Partnership strategies. In: Health promotion in community level: New Advances Edited by: Bracht N. Thousands Oak: SAGE publication; 1999:83-104.

63. Green LW, McAlister AL: Macro-intervention to support health behaviour change. Health Educ $Q$ 1 984, I I:322-339.

64. Kahssay HM, Taylor ME, Berman PE: ommunity Health Workers: The way forward. Geneva 1998.

65. Nutbeam D: Health promotion effectiveness: questions to be answered. In: The Evidence of Health Promotion Effectiveness: Shaping Public Health in New Europe Part 2 Evidence Book, A Report to European Commission by the International Union for Health Promotion and Education. Brussels 2000:I-I0.

66. Coons SJ, McGhan WF, Bootman JL, Larson LN: The effect of selfcare information on health-related attitudes and beliefs of college students. J Am Coll Health 1989, 38:12I-I24. [Pubmed Abstract]

67. Benson L, Nelson EC, Napps SE, Roberts E, Kane-Williams E, Salisbury ZT: Evaluation of the Staying Healthy After Fifty educational program: impact on course participants. Health Educ $Q$ 1989, 16:485-508. [Pubmed Abstract]

68. Mazzuca SA, Brandt KD, Katz BP, Chambers M, Byrd D, Hanna M: Effects of self-care education on the health status of innercity patients with osteoarthritis of the knee. Arthritis Rheum 1997, 40: 1466-1474. [Pubmed Abstract]

69. LeFort SM, Gray-Donald K, Rowat KM, Jeans ME: Randomized controlled trial of a community-based psychoeducation program for the self-management of chronic pain. Pain 1998, 74:297-306. [Pubmed Abstract]

70. Ersek M, Turner JA, McCurry SM, Gibbons L, Kraybill BM: Efficacy of a self-management group intervention for elderly persons with chronic pain. Clin J Pain 2003, 19:156-167. [Pubmed Abstract]

71. de Bruijn-Kofman AT, Van de Wiel H, Groenman NH, Sorbi MJ, Klip E: Effects of a mass media behavioral treatment for chronic headache: a pilot study. Headache 1997, 37:415-420. [Pubmed Abstract]

72. Von Korff M, Moore JE, Lorig K, Cherkin DC, Saunders K, Gonzalez VM, Laurent D, Rutter C, Comite F: A randomized trial of a lay person-led self-management group intervention for back pain patients in primary care. Spine 1998, 23:2608-2615. [Pubmed Abstract]

73. Little P, Roberts L, Blowers H, Garwood J, Cantrell T, Langridge J, Chapman J: Should we give detailed advice and information booklets to patients with back pain? A randomized controlled factorial trial of a self-management booklet and doctor advice to take exercise for back pain. Spine 200I, 26:2065-2072. [Pubmed Abstract]

74. Bower P, Richards D, Lovell K: The clinical and cost-effectiveness of self-help treatments for anxiety and depressive disorders in primary care: a systematic review. $\mathrm{Br} J$ Gen Pract 200I, 5 I:838-845. [Pubmed Abstract]

75. Lystad N, Heian F: Evaluation of a self-care leaflet. Tidsskr Nor Laegeforen 1989, 109:233-236. [Pubmed Abstract]

76. Lorig K, Gonzalez VM, Ritter P: Community-based Spanish language arthritis education program: a randomized trial. Med Care 1999, 37:957-963. [Pubmed Abstract]

77. Lorig KR, Ritter R, Stewart AL, Sobel DS, Brown BW Jr, Bandura A, Gonzalez VM, Laurent DD, Holman HR: Chronic disease selfmanagement program: 2-year health status and health care utilization outcomes. Med Care 200I, 39:1217-1223. [Pubmed Abstract]

78. Gibson H, Powell H, Coughlan J, Wilson AJ, Abramson M, Haywood P, Bauman A, Hensley MJ, Walter EH: Self management education and regular practitioner review for adults with asthma (Cochrane review). The Cochrane Library, June 3: Oxford Update software 2003.

79. Morrison EM, Lift HS: Health Maintenance organizations environment in the 1980s and beyond. Health Care Financ Rev 1990, 1 2:8I-90. [Pubmed Abstract]
80. Barlow SH, Burlingame GM, Nebeker RS, Anderson E: Meta-analysis of medical self-help groups. Int J Group Psychother 2000, 50:53-69. [Pubmed Abstract]

81. Kemper DW, Lorig K, Mettler M: The effectiveness of medical self-care interventions: $A$ focus on self-initiated responses to symptoms. Patient Educ Couns 1993, 2 1:29-39. [Pubmed Abstract]

82. Powell DR, Sharp SL, Farnell SD, Smith PT: Implementing a self care program. Effect on employee health care utilization. AAOHN J 1997, 45:. [Pubmed Abstract]

83. Hibbard JH, Greenlick M, Jimison H, Capizzi J, Kunkel L: The impact of a community-wide self-care information project on selfcare and medical care utilization. Eval Health Prof 200I, 24:404-423. [Pubmed Abstract]

84. InSight Consulting: [http://hwinfo.healthwise.org/healthwise/ items/document/e0388.pdf

\section{Pre-publication history}

The pre-publication history for this paper can be accessed here:

http://www.biomedcentral.com/1471-2458/4/11/prepub
Publish with Bio Med Central and every scientist can read your work free of charge

"BioMed Central will be the most significant development for disseminating the results of biomedical research in our lifetime. "

Sir Paul Nurse, Cancer Research UK

Your research papers will be:

- available free of charge to the entire biomedical community

- peer reviewed and published immediately upon acceptance

- cited in PubMed and archived on PubMed Central

- yours - you keep the copyright
BioMedcentral 